\title{
The association between birth condition and neuropsychological functioning and educational attainment at school age: a cohort study
}

\author{
David E Odd, ${ }^{1,2}$ Andrew Whitelaw, ${ }^{2}$ David Gunnell, ${ }^{3}$ Glyn Lewis ${ }^{4}$
}

${ }^{1}$ Neonatal Unit, Southmead Hospital, Bristol, Avon, UK ${ }^{2}$ Clinical Science at North Bristol, University of Bristol, Bristol, Avon, UK

${ }^{3}$ Department of Social Medicine, University of Bristol, Bristol, Avon, UK

${ }^{4}$ Department of Community Medicine, University of Bristol, Bristol, Avon, UK

\section{Correspondence to} David E Odd, Neonatal Unit, Southmead Hospital, Bristol BS10 5NB, UK:

david.odd@bristol.ac.uk

Accepted 12 June 2010 Published Online First 12 August 2010

\begin{abstract}
Objective Poor condition at birth may impact on 10 , although its effect on other measures of neurodevelopment is unclear. The authors' aim was to determine whether infants receiving resuscitation after birth have reduced scores in measures of attention, memory and language skills or the need for educational support at school even in the absence of clinical encephalopathy. Methods Three groups of term infants were identified from the Avon longitudinal study of parents and children: infants resuscitated at birth but asymptomatic for encephalopathy ( $n=612$ ), infants resuscitated who developed symptoms of encephalopathy $(n=40)$ and the reference infants who were not resuscitated and had no further neonatal care $(n=8080)$. Measures of attention, language, memory and the need for educational support were obtained for children between 8 years and 11 years. Test results (standardised to a mean of 100 and SD of 15) were adjusted for clinical and social covariates. Missing covariate data were imputed using chained equations.
\end{abstract}

Results Infants asymptomatic after resuscitation had similar scores to those not requiring resuscitation for all measures while infants who developed encephalopathy had lower working memory $(-6.65(-12.34$ to -0.96$))$, reading accuracy $(-7.95(-13.28$ to -2.63$))$ and comprehension (-9.32 (-14.47 to -4.17$)$ scores and increased risk of receiving educational support (OR 6.24 (1.52 to 26.43)) than infants thought to be well at birth, although there was little evidence for an association after excluding infants who developed cerebral palsy. Conclusions The authors found no evidence that infants who were resuscitated but remained well afterwards differed from those not requiring resuscitation in the aspects of neuropsychological functioning assessed in this study. Infants who developed neonatal encephalopathy had evidence of worse functioning, particularly in language skills and were more likely to receive educational support at school.

\section{INTRODUCTION}

It has been proposed that a "continuum of reproductive casualty' exists ${ }^{1}$ - that is, while profound perinatal events cause death or obvious neurological deficit, milder insults may cause more subtle defects in functioning only detectable as the child grows older. We have recently reported that infants with transient poor condition at birth had increased risk of low IO scores in childhood ${ }^{2}$ and early adulthood, ${ }^{3}$ although the impact on other measures of neurodevelopment is unclear. Abnormalities of attention, memory and language skills can have a profound impact on a

\section{What is already known on this topic}

- Infants who develop encephalopathy in the newborn period have increased risk of low 10 and other neurocognitive consequences.

- Infants who recover quickly from poor birth condition may also have increased risk of low IO scores later in life, but associations with other measures of neurocognition are unclear.

\section{What this study adds}

Infants who recover quickly from poor birth condition have similar scores for tests of memory, attention and language as infants thought to be well at birth.

child's scholastic abilities and their educational attainment.

One previous study in term infants showed no association of poor condition at birth with learning, behavioural or minor motor difficulties in infants who did not develop neurological signs in the neonatal period, although there was limited power to detect small differences. ${ }^{4}$ However, among preterm infants specific functional deficits may be greater than were predicted by the apparent IO deficits. ${ }^{5}$

The aim of this study was to investigate whether infants with physiological compromise at birth, measured as a clinical condition severe enough to warrant resuscitation, have poorer functioning in attention, memory and language skills or the need for educational support at school than those in good condition at birth even in the absence of clinical encephalopathy.

\section{METHODS}

\section{The Avon Longitudinal Study of Parents and} Children cohort

This study is based on the Avon Longitudinal Study of Parents and Children (ALSPAC) containing data on over 14000 infants and comprising children born in the Bristol area, England, between 1991 and 1992. Data on cohort members and their families are regularly collected using 
self-completed questionnaires, at half-day clinics or retrieved from routine medical or educational records.

\section{Measure of condition at birth}

Information on resuscitation and perinatal wellbeing was retrieved from the computerised records of all infants born in the two main maternity hospitals in the region (figure 1). Infants were considered to have evidence of physiological compromise if they required either positive pressure respiratory support (using a face mask or endotrachael tube) or cardiac compressions at birth. Seizures, jitteriness, high pitched cry, hypotonia or hypertonia or hyper-reflexia were considered to be indicators of encephalopathy. Measures of memory, attention and language were recorded at half-day clinics when the children were aged 8,9 and 11 years.

\section{Outcome measures}

Short-term memory was tested using the non-word repetition test ${ }^{6}$ at 8 years while working memory was assessed using the span score ${ }^{7}$ at 11 years of age. Attention skills were assessed at 8 years of age using the tasks taken from the test of everyday attention for children ${ }^{8}$ and tests of reading skills were derived from the Neale Analysis of Reading Ability ${ }^{9}$ at 9 years of age. Details of these tests are available on request.

\section{Measure of special educational needs}

Two measures of special educational needs (SEN) were used. At the age of 8 years the child's teacher was asked if the child had ever been identified as having SEN, and if they have a 'statement of special educational needs'. In the UK children may have a SEN produced for purely educational or other reasons (ie, physical disability leading to problems with attending school).

\section{Potential confounders and modifying variables}

The following perinatal and social factors were recorded for the infants:

- Antenatal factors: gender, maternal parity and maternal hypertension.

- Intrapartum factors: gestational age, birth weight, length and head circumference and mode of birth (ie, spontaneous cephalic, emergency or elective caesarean section, instrumental or breech).

- Social factors: maternal age, socioeconomic group ${ }^{10}$ and educational achievements, car ownership, housing tenure, crowding and ethnicity.

\section{Inclusion criteria}

This study is based on 11981 singleton infants from the ALSPAC cohort, born after 36 weeks of gestation at either of

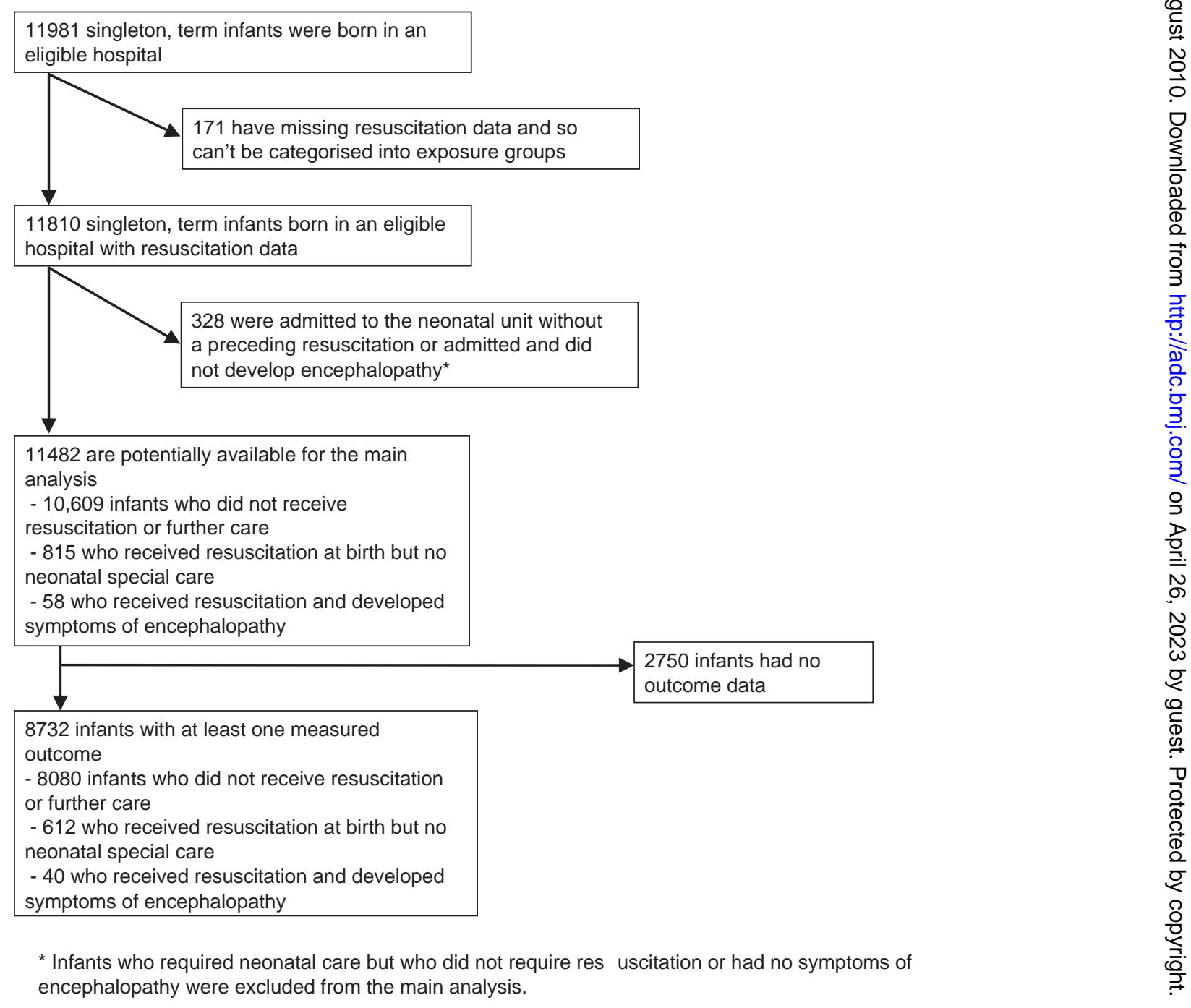

Figure 1 Data flow. 
the two major maternity units in the study area and alive at the age of 8 .

One hundred and seventy-one infants had missing data on resuscitation and so were removed from the dataset, while a further 328 infants who required neonatal care but who did not require resuscitation or had no symptoms of encephalopathy were excluded from the analysis to ensure other pathologies that may potentially influence IO did not lead to biased effect estimates. Infants were not excluded because of known learning difficulties or movement disorders. Three groups of infants were defined: (1) those receiving resuscitation but no further neonatal care ( $n=815),(2)$ those receiving resuscitation who progressed to develop symptoms or signs of encephalopathy ( $n=58)$ and (3) the reference group of well infants who did not require resuscitation or admission to the neonatal unit ( $n=10609)$; a total of 11482 infants. Associations of these measures with IQ at age 8 in this cohort have been previously reported. ${ }^{2}$

\section{Statistical analysis}

Linear regression models were used to investigate the association between birth condition and the continuous outcome measures (standardised within the dataset to a mean of 100 and $\mathrm{SD}$ of 15). Dual attention required log transformation to give a normally distributed measure. As not all infants completed all parts of the testing, each analysis contained a slightly different number of infants, ranging from 4445 (dual attention score) to 5894 (short-term memory). In addition, 3255 infants had missing data on at least one potential confounder. To reduce potential selection bias a missing data technique (multiple imputation using chained equations) was used to impute the missing confounder values ${ }^{11}$ only. All available exposure, outcome and covariate variables were used to impute the missing values. This allowed us to report analyses on the same number of subjects for both crude and adjusted analyses.

To investigate the effect of this missing data technique we performed a sensitivity analysis by repeating the analysis using a complete case analysis - that is, restricting the analysis to those participants with complete data on the exposure, outcome and confounder variables and using a fully imputed dataset (imputing the outcome status as well).

The effect of controlling for the possible confounding factors listed above was assessed and we also investigated whether associations differed by gender, parental occupation or education by fitting appropriate interaction terms to the models. The association between birth condition and a low score (defined as being in the lowest $10 \%$ of the cohort) for the above measures and those of educational need was assessed using logistic regression models. Finally, the analysis was repeated excluding those infants who developed cerebral palsy (CP) $(n=13)$.

We chose not to use Bonferonni corrections to adjust our $p$ values for the multiple statistical tests performed and report $p$ values and CI for individual evaluation. Scores for the measures of neurological functioning are strongly intercorrelated, or dependent, and so such an approach would be overly conservative. All analyses were conducted with Stata 10 software. Ethical approval for the study was obtained from the ALSPAC Law and Ethics Committee and the local research ethics committees.

\section{RESULTS}

In total, 2750 infants were excluded from all analyses because of absent data on all outcomes. There was little evidence that these infants with missing data were more likely to have needed resuscitation $(8.0 \%$ vs $7.5 \%, p=0.33)$. Table 1 shows the characteristics of the infants with any outcome measure recorded $(n=8732)$, split by their birth condition. Data were incomplete for some covariates, and consequently the denominator for different measures varies. Mothers with infants who were resuscitated tended to have lower educational levels than those whose children did not received support at birth. First pregnancy, maternal hypertension, maternal fever during labour and caesarean section all occurred more frequently in infants requiring resuscitation. Birth weight was slightly lower, head circumference slightly higher and Apgar scores considerably lower in infants who were resuscitated and rates of CP differed by birth condition $(p<0.001)$.

Mean scores for reading accuracy $(p=0.020)$ and comprehension $(p=0.006)$ differed between the three categories of birth condition, while there was weaker evidence that working memory scores differed depending on the birth condition $(p=0.065)$ (table 2). Table 3 shows the proportion of infants with a defined low score in each test. Risk of a low score in the comprehension test $(p<0.001)$ and the provision of an educational statement $(p=0.006)$ differed by birth condition, while there was weak evidence that the proportion of infants identified as having SEN depending on their birth condition $(\mathrm{p}=0.099)$.

In the final, adjusted linear regression model (table 4) there was little evidence for an association between any of the tests for memory, attention or language and the need for resuscitation among asymptomatic infants. Infants who developed encephalopathy following resuscitation had lower mean working memory ( -6.65 (CI -12.34 to -0.96$)$ ), reading accuracy $(-7.95$ (CI -13.28 to -2.63$))$ and comprehension $(-9.32$ (CI -14.47 to -4.17$)$ ) scores.

In the final logistic regression model (table 5) there was little evidence that resuscitated but asymptomatic infants had an increased risk of a low score in any measure, although adjusted ORs for six of the nine measures were indicative of worse outcomes in this group. Infants who developed encephalopathy following resuscitation had a higher risk of a low reading comprehension (OR 5.14 (2.06 to 12.80)), but limited evidence that they had higher risks of low scores in the other language, attention or memory tests, although the CI are wide and, for several measures, include the possibility of fourfold to fivefold increases in risk. Infants who developed encephalopathy also had substantially increased risk of having an educational statement (OR 6.24 (1.52 to 26.43)) or being reported to have SEN by their teacher (OR 3.10 (1.19 to 8.07)).

\section{Sensitivity analyses}

Repeating the analysis using infants with complete data only ('complete case analysis') produced stronger, but less precise, associations between resuscitation status and the need for an educational statement (asymptomatic infants, OR 1.69 (0.85 to 3.36), $\mathrm{p}=0.137$; encephalopathic infants, OR 8.57 (1.58 to 46.66), $\mathrm{p}=0.013)$. Repeating the analysis with a fully imputed dataset produced slightly weaker associations between resuscitation status and the need for an educational statement (asymptomatic infants, OR 1.37 (0.76 to 2.45), $\mathrm{p}=0.290$; encephalopathic infants, OR 7.17 (0.93 to 55.12), $\mathrm{p}=0.058$ ). When the analysis was repeated excluding infants who developed CP the association between birth condition and an educational statement weakened considerably (asymptomatic, OR 1.24 (0.65 to 2.38), $\mathrm{p}=0.511$; encephalopathic OR 2.14 (0.24 to 19.15), $\mathrm{p}=0.495)$. 
Table 1 Characteristics of the study population by resuscitation and presence or absence of encephalopathy

\begin{tabular}{|c|c|c|c|c|c|}
\hline \multirow[b]{2}{*}{ Measure } & \multirow[b]{2}{*}{ Number with data } & \multirow{2}{*}{$\begin{array}{l}\text { Infants not requiring } \\
\text { resuscitation }(\mathrm{n}=8080)\end{array}$} & \multicolumn{2}{|l|}{ Resuscitated infants } & \multirow[b]{2}{*}{ p Value } \\
\hline & & & Asymptomatic $(n=612)$ & Encephalopathic $(n=40)$ & \\
\hline \multicolumn{6}{|l|}{ Antenatal factors } \\
\hline Primiparous & 8223 & $3387(44.5 \%)$ & $327(56.6 \%)$ & $27(71.1 \%)$ & $<0.001$ \\
\hline Maternal hypertension & 8732 & $231(2.9 \%)$ & $26(4.3 \%)$ & $4(10.0 \%)$ & 0.005 \\
\hline \multicolumn{6}{|l|}{ Intrapartum factors } \\
\hline Birth length $(\mathrm{cm})$ & 8078 & $50.9(2.4)$ & $51.0(2.5)$ & $50.9(2.2)$ & 0.609 \\
\hline Head circumference $(\mathrm{cm})$ & 8100 & $34.9(1.4)$ & $35.0(1.4)$ & $35.0(1.6)$ & 0.009 \\
\hline Maternal fever & 8732 & $33(0.4 \%)$ & $7(1.1 \%)$ & $2(5.0 \%)$ & $<0.001$ \\
\hline Delivery & 8731 & & & & \\
\hline Spontaneous cephalic & & $6357(78.7 \%)$ & $317(51.9 \%)$ & $12(30.0 \%)$ & $<0.001$ \\
\hline Apgar at 1 minute & 8723 & $9(9-9)$ & $5(4-6)$ & $4(3-6)$ & $<0.001$ \\
\hline Apgar at 5 minute & 8723 & $10(9-10)$ & $9(8-9)$ & $8(6-9)$ & $<0.001$ \\
\hline \multicolumn{6}{|l|}{ Social factors } \\
\hline Maternal age (years) & 8732 & $28.5(4.8)$ & $28.5(4.7)$ & $28.2(4.9)$ & 0.923 \\
\hline Maternal socioeconomic group & 7603 & & & & \\
\hline i-professional & & $441(6.3 \%)$ & $32(6.1 \%)$ & $3(8.6 \%)$ & 0.243 \\
\hline ii-managerial & & $2284(32.4 \%)$ & $154(29.5 \%)$ & $6(17.1 \%)$ & \\
\hline iiiN_skilled non-manual & & $2781(39.5 \%)$ & $231(44.2 \%)$ & $17(48.6 \%)$ & \\
\hline iiiM—skilled manual & & $720(10.2 \%)$ & $58(11.1 \%)$ & $4(11.4 \%)$ & \\
\hline iv—semiskilled & & $672(9.5 \%)$ & $37(7.1 \%)$ & $5(14.3 \%)$ & \\
\hline $\mathrm{v}$-unskilled & & $147(2.1 \%)$ & $11(2.1 \%)$ & $0(0 \%)$ & \\
\hline Council rented & & $886(11.5 \%)$ & $65(11.1 \%)$ & $4(10.0 \%)$ & \\
\hline Private rented & & $691(9.0 \%)$ & $59(10.1 \%)$ & $4(10.0 \%)$ & \\
\hline Car ownership & 8306 & $7104(92.4 \%)$ & $537(91.8 \%)$ & $37(92.5 \%)$ & 0.853 \\
\hline Crowding index (number of people per room) & 8221 & & & & \\
\hline$<0.5$ & & $3359(44.2 \%)$ & $286(49.2 \%)$ & $23(59.0 \%)$ & 0.025 \\
\hline $0.5-0.75$ & & $3831(50.4 \%)$ & $257(44.2 \%)$ & $13(33.3 \%)$ & \\
\hline $0.75-1$ & & $296(3.9 \%)$ & $28(4.8 \%)$ & $3(7.7 \%)$ & \\
\hline $1+$ & & $115(1.5 \%)$ & $10(1.7 \%)$ & $0(0 \%)$ & \\
\hline Non-white ethnicity & 8659 & $388(4.8 \%)$ & $30(5.0 \%)$ & $4(10.0 \%)$ & 0.317 \\
\hline Cerebral palsy & 8732 & $7(0.1 \%)$ & $2(0.3 \%)$ & $3(5.0 \%)$ & $<0.001$ \\
\hline
\end{tabular}

$\mathrm{p}$ Values are for evidence for a difference between the three groups. Comparisons were made using analysis of variance or Kruskal-Wallis as appropriate.

Values are number (\%), median (IOR) or mean (SD) as appropriate.

${ }^{*}$ CSE, Certificate in Secondary Education (commonly taken at 16 years of age); vocational, City \& Guilds (intermediate level), technical, shorthand or typing, or other qualification; 0 level, ordinary level (commonly taken at 16 years of age); A level, advanced level (commonly taken at 18 years of age), state enrolled nurse, state registered nurse, City \& Guilds (final or full level) or teaching qualification; degree, University degree.

\section{Stratified results}

There was little evidence that the association between resuscitation and receiving an educational statement differed by maternal education $\left(p_{\text {interaction }}=0.787\right.$ ) or maternal socioeconomic group $\left(\mathrm{p}_{\text {interaction }}=0.240\right)$. However, there was evidence that the association between birth condition and receiving an educational statement differed by gender $\left(\mathrm{p}_{\text {interaction }}=0.007\right)$. When stratifying the results by gender, female infants had a higher risk of requiring a statement of educational need than males after poor condition at birth when compared to the reference group (asymptomatic infants: females OR 3.69 (1.60 to 8.51) vs males OR 0.71 (0.07 to 7.08), encephalopathic infants: females OR 9.36 (1.00 to 87.41) vs males OR 5.08 (0.28 to 93.42)), although CIs were wide. However, there was little evidence of a gender interaction with any other outcome.

\section{DISCUSSION \\ Principal findings}

Infants with neonatal encephalopathy had an increased risk of poor performance in memory and language testing as well 
Table 2 Mean values in memory, attention and language test scores at ages 8-11 years for resuscitated and non-resuscitated infants

\begin{tabular}{|c|c|c|c|c|}
\hline \multirow[b]{3}{*}{ Measure } & \multicolumn{4}{|l|}{ Mean (SD) scores } \\
\hline & \multirow{2}{*}{$\begin{array}{l}\text { Infants not requiring } \\
\text { resuscitation }\end{array}$} & \multicolumn{2}{|c|}{ Resuscitated infants } & \multirow[b]{2}{*}{ p Value } \\
\hline & & Asymptomatic & Encephalopathic & \\
\hline Non-word repetition (short-term memory) $(n=5894)$ & $100.0(15.0)$ & $100.4(15.7)$ & $103.3(14.4)$ & 0.450 \\
\hline Working memory (the span score) $(\mathrm{n}=5585)$ & $100.1(15.0)$ & $99.6(15.2)$ & $93.5(11.9)$ & 0.065 \\
\hline \multicolumn{5}{|l|}{ Tests of attention } \\
\hline \multicolumn{5}{|l|}{ Tests of language } \\
\hline Accuracy $(n=5529)$ & $100.0(15.0)$ & $100.3(15.2)$ & $92.1(13.7)$ & 0.020 \\
\hline Read per minute $(n=5519)$ & $100.0(15.0)$ & $100.0(15.3)$ & $95.9(17.0)$ & 0.341 \\
\hline Comprehension $(n=5529)$ & $100.0(14.9)$ & $100.0(15.8)$ & $90.9(16.4)$ & 0.006 \\
\hline
\end{tabular}

$\mathrm{p}$ Values are for comparison between all three groups.

Table 3 Proportion of children with low scores* for tests of memory, attention and language and with special educational needs at ages 8-11 years according to resuscitation status

\begin{tabular}{|c|c|c|c|c|}
\hline \multirow[b]{3}{*}{ Measure } & \multicolumn{4}{|c|}{ Number (\%) with a low score } \\
\hline & \multirow{2}{*}{$\begin{array}{l}\text { Infants not requiring } \\
\text { resuscitation (\%) }\end{array}$} & \multicolumn{2}{|l|}{ Resuscitated infants } & \multirow[b]{2}{*}{ p Value } \\
\hline & & Asymptomatic (\%) & Encephalopathic (\%) & \\
\hline Non-word repetition (short-term memory) $(n=5894)$ & $439(8.0)$ & $38(9.6)$ & $0(0)$ & 0.186 \\
\hline Working memory (the span score) $(n=5585)$ & $229(4.4)$ & $18(4.7)$ & $2(7.4)$ & 0.730 \\
\hline \multicolumn{5}{|l|}{ Tests of attention } \\
\hline \multicolumn{5}{|l|}{ Tests of language } \\
\hline Accuracy $(n=5529)$ & $541(10.5)$ & $37(10.1)$ & $6(21.4)$ & 0.167 \\
\hline Read per minute $(n=5519)$ & $514(10.0)$ & $37(10.1)$ & $5(17.9)$ & 0.389 \\
\hline Comprehension $(n=5529)$ & $490(9.5)$ & $42(11.5)$ & $9(32.1)$ & $<0.001$ \\
\hline \multicolumn{5}{|l|}{ School performance } \\
\hline
\end{tabular}

$\mathrm{p}$ Values are for comparison between all three groups.

${ }^{*} \mathrm{~A}$ low score is defined as being in the lowest $10 \%$.

as an increased risk of being assessed as having SEN at age 8 years, although there was evidence that the effect may have differed by gender, and there was little evidence for an association after excluding infants who developed CP. There was no evidence that infants who required resuscitation but did not develop encephalopathy had impairments of memory, attention, language or school performance.

\section{Possible mechanisms}

Previously we have shown in both this cohort ${ }^{2}$ and a cohort of 100000 Swedish conscripts $^{3}$ that infants with poor birth condition, even if they did not develop neurological signs at birth, had lower IO scores than a reference group at age 8 and 18 years, respectively. These data suggest that mild perinatal physiological compromise may be associated with subtle neuronal or synaptic damage and affect cognition later in life, although it is possible that the apparent long-term outcomes may be due to in utero neuropathology presenting with poor condition at birth. However, in the study of Swedish conscripts, ${ }^{3}$ as in the present study, a weaker association was seen with school performance than $\mathrm{IQ}$, perhaps reflecting the wider range of social and economic influences on educational outcomes. While school performance could be considered a more pragmatic measure of function there was also little evidence that transient poor condition at birth was associated with the neuropsychological functions we assessed, despite the previously reported association with IO score. ${ }^{2}$ It is possible that there are other neuropsychological functions, sensitive to damage around birth, that contribute to IQ scores and that we have not measured in this study. Of course the wide CI seen in these analyses reflects a lack of precision in these measures in contrast to the Wechsler Intelligence Scale for children-III IQ assessment. In contrast, and compatible with the existing literature, infants who develop encephalopathy in the neonatal period have both lower IO scores than their peers and worse functioning in memory, language and attention, although evidence for an impact on attention was weak. The localisation of specific brain functions to specific anatomical areas is difficult. Working memory in children has been shown to be more localised in the caudate nucleus and anterior insula than in the dorsolateral prefrontal cortex as in adults, ${ }^{12}$ while comprehension has not been consistently localised to one area. ${ }^{13} 14$ Furthermore different profiles of ischaemic damage are likely to involve different areas of the newborn brain. ${ }^{15}$

The weakening of the association after removal of infants with CP may reflect simply reduced precision from lower numbers, although it is consistent with the belief that those infants with CP represent a subgroup of infants with more substantial asphyxial insults. 
Table 4 Difference in mean memory, attention and language test scores at ages 8-11 years for resuscitated infants compared to those who were not resuscitated, split by birth condition

\begin{tabular}{|c|c|c|c|c|}
\hline & $\begin{array}{l}\text { Unadjusted mean difference } \\
(95 \% \text { CI })\end{array}$ & p Value & $\begin{array}{l}\text { Adjusted mean difference } \\
(95 \% \mathrm{Cl})^{*}\end{array}$ & p Value \\
\hline \multicolumn{5}{|l|}{ Tests of memory } \\
\hline \multicolumn{5}{|l|}{ Non-word repetition (short-term memory) $(\mathrm{n}=5894)$} \\
\hline Encephalopathic infants & $3.37(-2.5$ to 9.27$)$ & 0.262 & $2.57(-3.25$ to 8.39$)$ & 0.386 \\
\hline \multicolumn{5}{|l|}{ Working memory (the span score) $(n=5585)$} \\
\hline Resuscitated infants without encephalopathy & $-0.45(-2.01$ to 1.11$)$ & 0.572 & $-0.57(-2.18$ to 1.04$)$ & 0.485 \\
\hline \multicolumn{5}{|l|}{ Tests of attention } \\
\hline \multicolumn{5}{|l|}{ Sky search attention $(\mathrm{n}=5752)$} \\
\hline Resuscitated infants without encephalopathy & $0.94(-0.59$ to 2.49$)$ & 0.228 & $1.10(-0.49$ to 2.69$)$ & 0.175 \\
\hline Encephalopathic infants & $1.84(-4.17$ to 7.87$)$ & 0.547 & $0.99(-5.01$ to 7.00$)$ & 0.747 \\
\hline \multicolumn{5}{|l|}{ Dual attention score $(n=4445)$} \\
\hline Resuscitated infants without encephalopathy & $-0.18(-1.97$ to 1.61$)$ & 0.845 & $-0.22(-2.07$ to 1.63$)$ & 0.813 \\
\hline Encephalopathic infants & $-7.88(-13.46$ to -2.31$)$ & 0.006 & $-7.95(-13.28$ to -2.63$)$ & 0.003 \\
\hline \multicolumn{5}{|l|}{ Read per minute $(n=5519)$} \\
\hline Resuscitated infants without encephalopathy & $-0.04(-1.63$ to 1.56$)$ & 0.963 & $0.00(-1.58$ to 1.58$)$ & 0.998 \\
\hline Encephalopathic infants & $-4.17(-9.75$ to 1.41$)$ & 0.143 & $-4.49(-9.86$ to 0.88$)$ & 0.101 \\
\hline \multicolumn{5}{|l|}{ Comprehension $(n=5529)$} \\
\hline Resuscitated infants without encephalopathy & $-0.01(-1.60$ to 1.59$)$ & 0.992 & $-0.03(-1.55$ to 1.48$)$ & 0.968 \\
\hline Encephalopathic infants & $-9.10(-14.67$ to 3.53$)$ & 0.001 & $-9.32(-14.47$ to -4.17$)$ & $<0.001$ \\
\hline
\end{tabular}

*Adjusted for gender, parity, birth weight, length and head circumference, mode of delivery, maternal hypertension, fever, age, education status, socioeconomic position, housing tenure and crowding index, car ownership and ethnicity.

Values are mean difference from the non-resuscitated infants' mean $(95 \% \mathrm{Cl})$.

Consistent with the wider literature, male infants were more likely to have an educational statement than females (4.3\% vs $1.7 \%, p<0.001)$. However, there was evidence that the effect may have differed by gender, with limited evidence that poor birth condition was associated with educational statementing in males. It is possible that birth condition may selectively affect female infants in ways unmeasured by this paper. However, it may be a chance finding and there was little evidence to suggest that an effect on memory, attention, language or $\mathrm{IQ}^{3}$ are modified in this way.

\section{Strengths and limitations}

The proportion of infants receiving resuscitation in this cohort $(7.5 \%)$ is consistent with the literature, although published rates (all gestations) vary between $1 \%{ }^{16}$ and $14 \% .{ }^{17}$ This variation may reflect partly subjective decisions by clinicians to initiate resuscitation and consequently some degree of measurement error is likely. The analysis was based on a large cohort of infants with detailed outcome data and we were able to control for a number of common prenatal pathologies and excluded infants admitted to the neonatal unit without a clear diagnosis. An important limitation to our study is the amount of missing data in this analysis, although using three methods of analysing the data produced similar results. Although ALSPAC was not designed with the diagnostic criteria for encephalopathy, seizures, jitteriness, high pitched cry, hypotonia or hypertonia or hyper-reflexia were, by the standards of 1990, reasonable indicators of encephalopathy. ${ }^{18}$

\section{Comparisons with other studies}

Few studies have investigated the association between birth condition and measures of neuropsychological functioning and educational attainment in childhood in infants who do not develop encephalopathy. Moster et al ${ }^{4}$ reported on the risk of a range of neurological functions in a cohort of 727 infants with low Apgar scores at birth. Their findings are similar to ours (eg, children with a 5-minute Apgar score of 3 with signs consistent with neonatal encephalopathy had increased risk of extra resources in at school (OR 3.4 (1.8 to 6.3)), although the number of infants with low Apgar scores was low, and consequently the CIs around the point estimates were wide. In contrast, many studies have reported that infants surviving hypoxicischaemic encephalopathy have increased risk of language, ${ }^{19} 20$ attention ${ }^{20}$ and memory functioning 2021 impairment.

\section{CONCLUSIONS}

In the ALSPAC cohort, we could not find evidence to support a difference in tests of memory, attention or language between infants who received resuscitation but remained well afterwards and those thought to be well at birth. While apparently transient degrees of perinatal asphyxia are associated with worse IQ scores later in life, these same infants appear to function at a similar level to their peers in these specific areas. In contrast, infants who developed neonatal encephalopathy had worse functioning, particularly in language skills, and were six times more likely to receive a statement of educational need. While care should be taken in the follow-up of infants with encephalopathy it appears that in the functions measured here, infants who recover quickly from poor birth condition require no further educational support than their peers.

Acknowledgements We are extremely grateful to all the families who took part in this study, the midwives for their help in recruiting them and the whole ALSPAC team, which includes interviewers, computer and laboratory technicians, clerical 
Table 5 OR for low test score results* or the requirement for special educational needs for resuscitated infants compared to those not resuscitated, according to condition at birth

\begin{tabular}{|c|c|c|c|c|}
\hline & Unadjusted OR (95\%CI) & p Value & Adjusted OR (95\%Cl)† & p Value \\
\hline \multicolumn{5}{|l|}{ Tests of memory } \\
\hline \multicolumn{5}{|l|}{ Non-word repetition (short-term memory) $(\mathrm{n}=5894)$} \\
\hline Normal infants & 1.00 (ref) & & 1.00 (ref) & \\
\hline Resuscitated infants without encephalopathy & $1.21(0.85$ to 1.71$)$ & 0.284 & $1.23(0.85$ to 1.78$)$ & 0.279 \\
\hline Encephalopathic infants & NA & & NA & \\
\hline \multicolumn{5}{|l|}{ Working memory (the span score) $(n=5585)$} \\
\hline Encephalopathic infants & $1.73(0.41$ to 7.35$)$ & 0.458 & $1.72(0.38$ to 7.86$)$ & 0.482 \\
\hline \multicolumn{5}{|l|}{ Tests of attention } \\
\hline \multicolumn{5}{|l|}{ Sky search attention $(n=5752)$} \\
\hline Normal infants & 1.00 (ref) & & 1.00 (ref) & \\
\hline Resuscitated infants without encephalopathy & 0.91 (0.65 to 1.28$)$ & 0.591 & 0.86 (0.60 to 1.24$)$ & 0.412 \\
\hline Encephalopathic infants & $0.75(0.17$ to 3.20$)$ & 0.694 & 0.83 (0.19 to 3.69$)$ & 0.811 \\
\hline Encephalopathic infants & 2.35 (0.77 to 7.17$)$ & 0.134 & $2.55(0.81$ to 8.06$)$ & 0.111 \\
\hline \multicolumn{5}{|l|}{ Tests of language } \\
\hline \multicolumn{5}{|l|}{ Accuracy $(n=5529)$} \\
\hline Normal infants & 1.00 (ref) & & 1.00 (ref) & \\
\hline Resuscitated infants without encephalopathy & 0.96 (0.67 to 1.36$)$ & 0.811 & 0.98 (0.67 to 1.43$)$ & 0.933 \\
\hline Encephalopathic infants & 2.32 (0.93 to 5.74$)$ & 0.070 & $2.18(0.80$ to 5.93$)$ & 0.126 \\
\hline \multicolumn{5}{|l|}{ Read per minute $(n=5519)$} \\
\hline Normal infants & 1.00 (ref) & & 1.00 (ref) & \\
\hline Resuscitated infants without encephalopathy & 1.01 (0.71 to 1.44$)$ & 0.946 & 1.02 (0.70 to 1.51$)$ & 0.892 \\
\hline Encephalopathic infants & 1.95 (0.74 to 5.16$)$ & 0.178 & $1.81(0.62$ to 5.25$)$ & 0.274 \\
\hline \multicolumn{5}{|l|}{ Comprehension $(n=5529)$} \\
\hline Normal infants & 1.00 (ref) & & 1.00 (ref) & \\
\hline \multicolumn{5}{|l|}{ Statemented $(n=5082)$} \\
\hline Normal infants & 1.00 (ref) & & 1.00 (ref) & \\
\hline Resuscitated infants without encephalopathy & 1.34 (0.76 to 2.34$)$ & 0.307 & $1.36(0.74$ to 2.50$)$ & 0.322 \\
\hline Encephalopathic infants & $5.62(1.64$ to 19.36$)$ & 0.006 & $6.24(1.52$ to 26.43$)$ & 0.011 \\
\hline
\end{tabular}

${ }^{*}$ A low score is defined as being in the lowest $10 \%$.

†Adjusted for gender, parity, birth weight, length and head circumference, mode of delivery, maternal hypertension, fever, age, education status, socioeconomic position, housing tenure and crowding index, car ownership and ethnicity.

‡Not estimatable owing to no infants with a low score in the encephalopathic group.

Values are $\mathrm{OR}(95 \% \mathrm{Cl})$.

workers, research scientists, volunteers, managers, receptionists and nurses. The UK Medical Research Council, the Wellcome Trust and the University of Bristol provide core support for ALSPAC. This publication is the work of the authors and $D E 0, G L, A W$ and DG will serve as guarantors for the contents of this paper.

Funding This research was funded by the Wellcome Trust fellowship award (077036) to DEO. Role of sponsor: The funding organisation did not participate in the design and conduct of the study, in the collection, analysis, and interpretation of the data, or in the preparation, review or approval of the manuscript.

Competing interests None.

Ethics approval This study was conducted with the approval of the ethical approval for the study was obtained from the ALSPAC Law and Ethics Committee and the local research ethics committees.

Provenance and peer review Not commissioned; externally peer reviewed.

Contributors Study concept and design: DEO, AW, DG, GL; analysis and interpretation of data: DEO, AW, DG, GL; drafting of the manuscript: DEO; critical review of the manuscript for important intellectual content: DEO, AW, DG, GL; statistical analysis: DEO; obtain funding: DEO, AW, DG, GL.

\section{REFERENCES}

1. Pasamanick B, Knobloch H. Brain and behavior. Symposium, 1959. 2. Brain damage and reproductive casualty. Am J Orthopsychiatry 1960;30:298-305.

2. Odd DE, Lewis $G$, Whitelaw A, et al. Resuscitation at birth and cognition at 8 years of age: a cohort study. Lancet 2009;373:1615-22.

3. Odd DE, Rasmussen F, Gunnell D, et al. A cohort study of low Apgar scores and cognitive outcomes. Arch Dis Child Fetal Neonatal Ed 2008;93:F115-20.

4. Moster D, Lie RT, Markestad T. Joint association of apgar scores and early neonatal symptoms with minor disabilities at school age. Arch Dis Child Fetal Neonatal Ed 2002;86:F16-21.

5. Marlow N, Hennessy EM, Bracewell MA, et al. Motor and executive function at 6 years of age after extremely preterm birth. Pediatrics 2007;120:793-804.

6. Gathercole SE, Baddeley AD. The children's test of non-word repetition. Sidcup UK: The Psychological Corporation, 1996. 
7. Case R, Kurland D, Goldberg J. Operational efficiency and the growth of shortterm-memory span. J Exp Child Psychol 1982;33:386-404.

8. Manly T, Anderson V, Nimmo-Smith I, et al. The differential assessment of children's attention: the test of everyday attention for children (TEA-Ch), normative sample and ADHD performance. J Child Psychol Psychiatry 2001;42:1065-81.

9. Neale MD. Neale analysis of reading ability. 2nd ed. Windsor, Ontario, Canada: NFER-NELSON, 1997

10. Office for National Statistics. Standard Occupational Classification. Vol 3, 1991.

11. Royston P. Multiple Imputation of missing values: update. Stata J 2005;5:681-201.

12. Scherf KS, Sweeney JA, Luna B. Brain basis of developmental change in visuospatial working memory. J Cogn Neurosci 2006;18:1045-58.

13. Karunanayaka PR, Holland SK, Schmithorst VJ, et al. Age-related connectivity changes in $\mathrm{fMRI}$ data from children listening to stories. Neuroimage 2007:34:349-60.

14. Vannest J, Karunanayaka PR, Schmithorst VJ, et al. Language networks in children: evidence from functional MRI studies. AJR Am J Roentgenol 2009:192:1190-6.
15. Myers RE. Two patterns of perinatal brain damage and their conditions of occurrence. Am J Obstet Gynecol 1972;112:246-76

16. Palme-Kilander C. Methods of resuscitation in low-Apgar-score newborn infants - a national survey. Acta Paediatr 1992;81:739-44.

17. Kroll L, Twohey L, Daubeney PE, et al. Risk factors at delivery and the need for skilled resuscitation. Eur J Obstet Gynecol Reprod Biol 1994;55:175-7.

18. Sarnat HB, Sarnat MS. Neonatal encephalopathy following fetal distress. A clinical and electroencephalographic study. Arch Neurol 1976;33:696-705.

19. Robertson CM, Finer NN. Educational readiness of survivors of neonatal encephalopathy associated with birth asphyxia at term. J Dev Behav Pediatr 1988;9:298-306

20. Marlow N, Rose AS, Rands CE, et al. Neuropsychological and educational problems at school age associated with neonatal encephalopathy. Arch Dis Child Fetal Neonatal Ed 2005;90:F380-7.

21. Lindström K, Lagerroos P, Gillberg C, et al. Teenage outcome after being born at term with moderate neonatal encephalopathy. Pediatr Neurol 2006:35:268-74. 